\title{
The role of academic libraries in the enhancement of information literacy: a study of Fort Hare Library
}

\author{
Ntombizodwa G. Somi \\ Gold Fields Library, Vaal University of Technology, South Africa \\ zodwa@vut.ac.za \\ and \\ Karin de Jager ${ }^{2}$ \\ Department of Information and Library Studies, University of Cape Town \\ kdejager@ched.uct.ac.za
}

\begin{abstract}
Received: 2 Ist June 2005
Accepted: $7^{\text {th }}$ October 2005

Students today are faced with many difficulties in finding information, because new technology makes information available in different, mainly electronic, formats. For this information to be accessed and used properly, students are required to be information literate. It is a duty of today's libraries to equip students with the necessary information skills to function effectively and to meet challenges of the information age. This paper reports on an investigation into the role of the University of Fort Hare Library in the enhancement of students' information literacy. A survey was conducted among both undergraduate and postgraduate students and results of a total of 246 responses were analysed. Findings show that while there is some evidence that the University of Fort Hare Library is engaging in information literacy activities, students still have difficulty in finding, critically evaluating and using information.
\end{abstract}

Key words: Academic libraries; information literacy; Fort Hare Library

\section{Introduction}

The information revolution has vastly increased the importance of being able to access and utilize information from a variety of sources, including information published electronically (Fahey, 2003:173). Much of this information comes unfiltered by peer review and this raises questions about authenticity, validity and reliability. In turn, these questions pose special challenges in evaluating, understanding and using information in an ethical and legal manner. The uncertain quality and expanding quantity of information also poses large challenges for organizations and for society itself (Bundy, 200I).

Today's technological changes require societies to have certain capabilities (other than the ability to read and write) to fully utilize these resources. Haberle (2002: 22) asserts that society requires multi-skilled learners, who are able to think critically, pose and solve problems, and become independent and lifelong learners. If people are unable to access information, observes Fahey (2003:173), they will be faced with information poverty, which she defines as a form of poverty that leads to disadvantage due to a lack of access to all types of information.

It is also important that learners acquire an understanding of the technological environment in which information resources are integrated and used (Brandt, 200I), as it is not just the finding of information, but the ability to use it that is important. Educational institutions should provide opportunities for ensuring that all students acquire competence in knowing how to learn, to formulate questions, to access potential sources of information, to evaluate what is found for accuracy and pertinence, to organize information, and finally, to use information to do something, the last and most valuable step in the process (Doyle, 2003).

To be able to actually use information, Doyle further affirms that students need to be thoughtfully engaged with new information, to connect facts with what they already know. They need to become involved with discovering information and be able to communicate their new understanding in a meaningful way because information is not knowledge until one is able to do something with it.

Technological developments indeed have not only affected the way societies conduct their businesses, they have also impacted libraries worldwide. In South Africa, libraries that offered user education programmes have for some time been faced with the major challenge of making users information literate as opposed to library literate (Behrens 1992:81). Library goals should be expanded from providing library user education and teaching library instruction, to inculcating

I. Ntombizodwa G. Somi is a Subject Librarian at Gold Fields, Vaal University of Technology, South Africa

2. Karin de Jager is Associate Professor of Information and Library Studies, University of Cape Town, South Africa 
information literacy and lifelong learning (Tiefel, 1995:318). For libraries to meet the present challenges of the information age, they should engage in student learning and empower students with essential information skills. Mastering information literacy skills in an academic context should enable students to function effectively during their academic years and beyond.

The aim of this paper has been to look at the role played by academic libraries in the enhancement of information literacy with specific reference to the University of Fort Hare Library. The research questions therefore focused on whether:

- Students understand the importance of library orientation?

- Students know how to locate information in the library?

- Training on the OPAC and other online databases help students to search independently?

- Students know how to evaluate information critically?

- Students know how to quote and cite information retrieved?

\section{The nature of information literacy}

A widely used and accepted definition of information literacy from the American Library Association Presidential Committee, states that information literacy is:

'A set of abilities requiring individuals to recognize when information is needed and have the ability to locate evaluate and use effectively the needed information' (ALA: 1989).

The widely agreed characteristics of information literate persons are defined by De Jager and Nassimbeni (2002:168) as those who can:

I. 'Recognize the need for information;

2. Access information efficiently and effectively;

3. Evaluate information and its sources critically;

4. Incorporate selected information into one's knowledge base;

5. Use information effectively to accomplish a specific purpose;

6. Understand the economic, legal and social issues surrounding the use of information;

7. Access and use information ethically and legally.'

Adler (1999) and McClure (1994: II5-I I6) made it clear that that information literacy is not the same as library literacy, media literacy, computer literacy or network literacy; but is a concept that encompasses other literacies. Bruce (1997:2) asserts that other literacy concepts coexist with the idea of information literacy, but each is systematically differentiated or incorporated into the description of information literacy. Langford (1999) sees these components as necessary enhancers of information literacy.

Langford (1999) and McClure (1994) describe an information literate person as a person who should be able to locate and access information in all its forms. Langford then perceives information literacy as a goal which can be attained through a process that relies on the continuous learning of specific and evolving behaviours, and as a cluster of abilities which individuals can employ to cope with and take advantage of the unprecedented amount of information which surround them in their daily life and work. Information literacy presents a broad approach that offers the opportunity to educate students to understand the importance of information, and have the competence to locate, evaluate and manage it. In that way, it contributes towards a higher level of literacy and lifelong learning (Makhubela and Koen, 1995:13).

Computers and web skills are essential today, but this does not mean that emphasis should be on teaching students to be computer literate or web literate only. Acquiring these competencies do not guarantee that information literacy is achieved. Students are information literate when they are comfortable in using all information formats independently, when they are able to evaluate and base decisions on information obtained. The duty of academic librarians in partnership with other stakeholders is to empower students to be literate and comfortable in using information available in printed and in electronic formats.

\section{Information literacy in academic libraries in South Africa}

Responding to developments outlined above, South African academic libraries have in recent years increasingly engaged in activities intended to help students to become critical thinkers, problem solvers, independent information seekers and lifelong learners. In an extensive investigation over a number of years, De Jager and Nassimbeni have charted the development of librarians' perceptions of information literacy and the extent of their information literacy interventions in South African Higher Education Institutions (De Jager and Nassimbeni, 2002, 2003, 2005). By using complementary approaches such as workshops and surveys, they could show how interventions have developed from mainly generic courses for undergraduate students from different disciplines (2002: 174), to a growing recognition that information literacy should be integrated into credit-bearing courses in curricula so that 'teaching information skills should be firmly 
embedded in subject knowledge' (2002:175). They were able to demonstrate that a steadily increasing number of librarians were actually collaborating with academics to produce courses that integrated information literacy into curricula (2005:36), but they also had to conclude that while librarians might be aware of the importance of working together with academics to incorporate information literacy into credit-bearing courses, many librarians were still 'most comfortable with the traditional "information skills" component of information literacy education' (2005:27) so that many courses were still of a generic and standalone nature.

\subsection{Information literacy at the University of Fort Hare Library}

The library is making its voice heard throughout the university. Its voice is supported in its new mission statement, which reads as follows:

'The role of the library is to provide appropriate information resources and instruction in their use, sufficient to meet the educational, recreational and research needs of staff, students and community users through the effective acquisition and organization of material and technological resources' (University of Fort Hare General Prospectus, 2004: 86).

One of the ways in which the library achieves these aims is by providing orientation to students, especially to newcomers. This takes place at the beginning of the year. The objective is for newcomers to become familiar with the library services. The focus is on:

I. Types of information sources - how to access and locate these information sources

2. What to do when the required source of information is out on loan or is not available in the library

3. How to use library facilities like photocopies and computers

4. Rules and regulations of the library

In addition, there are on-going intensive training sessions that are conducted by information librarians. The targeted groups include lecturing staff and students, especially senior students. Their focus is on:

I. The effective use of the OPAC

2. The effective use of online databases

3. Usage of the Internet

4. Methods of online citation

Manuals for various online databases, the OPAC and guides for effective use of online resources are provided during these sessions. At the end of each training session, students are given assessment forms where they are asked to provide brief feedback on each session. The feedback provided helps the library to improve its services to these students.

Occasionally lecturing staff responsible for certain subjects send their students to the library to be trained more specifically in the identification and use of information resources of their particular subject areas. This is called Subject Orientation. Appointments for these programmes are made in advance to allow information librarians to collect enough information pertaining to the subject concerned. At the end of the session, students are meant to be able to use information resources that the library has on that particular subject. The use of the library home page on the web where students learn about the library services, the evaluation of online resources, databases, writing assignments, citation styles and library rules and regulations are also taught during these sessions.

While the library aims to equip its learners with lifelong skills, there is an additional, optional computer literacy training course that is conducted by the Computer Centre. This is a three months course for which an additional fee of RI500 has to be paid, and classes are conducted in the evenings. The focus is on teaching students the basic components of a computer and how to use Microsoft Word, Excel, Power-point, Microsoft Access, and the Internet. Those who manage to finish the course are awarded Computer Literacy Certificates. Because of the payment involved and because the course is not integrated into the curriculum only a few students are able to participate. Students, who are unable to afford the course, lack these computer skills.

\section{Methodology}

The aim of the study was to investigate the extent to which the University of Fort Hare Library promotes and enhances information literacy. A survey method using questionnaires containing both closed and open-ended questions was chosen. Both undergraduate and postgraduate students completed questionnaires about their experiences in the library and their use of library materials.

The University of Fort Hare Library was used as the venue for the distribution of the questionnaires. A covering letter stating the purpose of the research and the deadline for the return of the questionnaires was attached to each questionnaire. A total of three hundred questionnaires was distributed among students entering the library. The distribution was conducted during morning, afternoon and evening sessions. Twenty questionnaires were distributed during each session. A distribution plan was used to record responses received at the end of each day. This was done 
within one week over fifteen sessions. An initial problem of a low return rate was overcome by putting notices up in the Library encouraging respondents to return their questionnaires, so that a total of 246 questionnaires $(82 \%)$ was eventually received.

The questions were designed to elicit responses about library user education, students' use of library information resources and their use of the Internet. With regard to user education, the questionnaire focused on:

I. Location and arrangement of library resources

2. Types of information resources

3. Benefits of library orientation

4. Students' ability to use library resources

5. Training in the use of online resources

6. Knowledge and use of search engines and the Internet

7. Evaluation and citation of Internet resources.

The questionnaire consisted of both closed questions, where students had to select one or more correct answers, and open-ended questions for which they had to write in their own answers. Closed questions were coded and counted and the results entered into tables. Open-ended questions were counted, classified and ranked in order to reflect frequency of responses.

\section{Results}

The survey was conducted to ascertain whether the Fort Hare Library was successfully providing students with information skills for their academic needs. The main findings are considered below:

5.1 Library orientation

Orientation is offered to all new students that enrol at the University for the first time, and is intended to help close the gap between high school and tertiary education. The students were asked whether they had attended the library orientations sessions conducted by the library, and what they have learned from the library orientation. It was found that the majority of respondents $(13 \mathrm{I} ; 53 \%)$ had not attended library orientation, which is compulsory, but is offered during the first week of term only. Possible reasons for this anomaly are the late admission of substantial numbers of South African students, and the late arrival of new students from other parts of Africa.

5.2 What was learned from orientation?

The next question asked those students who had responded positively to the previous question to indicate what they had learnt from attending library orientation. Respondents could tick as many activities as applied. Their responses are summarised in Table I.

Table I Lessons from the orientation

\begin{tabular}{lll}
\hline Activities & Responses & Percentage of respondents \\
\hline Photocopying & 87 & 76 \\
Library rules and regulations & 74 & 64 \\
Using reference materials & 69 & 60 \\
Searching books (OPAC) & 39 & 34 \\
Using print journals & 35 & 30 \\
\hline TOTAL & $\mathbf{3 0 4}$ & $\mathbf{( n = ~ I ~ I 5 ) ~}$
\end{tabular}

Findings above suggest that the information literacy of participants who attended the library orientation sessions had not necessarily been enhanced to a considerable extent. For example of the II 5 that attended the library orientation, only 39 responses (34\%) showed that they learnt how to use OPAC, while only $35(30 \%)$ indicated that they learnt how to use print journals. From this we conclude that the library orientation sessions currently conducted do not succeed in their aim of empowering students to use library materials and services. Of those that attended library orientation, the highest number of responses $(87 ; 76 \%)$ claimed that one of the things they learnt to do is the basic activity of photocopying, which is demonstrated in these sessions.

\subsection{Sources of information}

Respondents were asked to choose the one source of information that they consult first when given an assignment. Browsing the open shelves to find information was the most frequent response, as 88 out of $246(36 \%)$ indicated that this is their preferred activity. Even though Internet resources generally need careful evaluation, $70(28 \%)$ of the respondents regard this source of information as their first stop towards fulfilling their information needs. The reference section where sources such as dictionaries, encyclopaedias, dictionaries, biographies and world bank reports are found, was selected by 
32 respondents (13\%) and 29 (I2\%) went to information librarians to help them to find information. Only 19 (8\%) first use the OPAC to check which books are available in the library. The online databases, to which the library subscribes, are used least, as just 8 respondents (3\%) selected this activity. This finding is a cause for concern as the library spends a significant amount of money on these subscription databases which the students seem to be unwilling or unable to use.

\subsection{Location of library sources}

After asking about sources of information that respondents use when given assignments, respondents were asked to specify how they locate information sources in the library and the findings are summarised in Table 2:

Table 2 Location of materials in the library $(\mathrm{N}=246)$

\begin{tabular}{lll}
\hline How do they locate information? & Respondents & Percentage \\
\hline Use the OPAC & 101 & 41 \\
Browse the open shelves & 80 & 33 \\
Ask library staff & 57 & 23 \\
Ask a friend & 8 & 3 \\
\hline TOTAL & $\mathbf{2 4 6}$ & 100 \\
\hline
\end{tabular}

Strangely enough, the largest number of respondents $(101 ; 41 \%)$ indicated that they locate information by using the OPAC, while only $80(33 \%)$ prefer browsing, This finding is interesting, as only $8 \%$ of respondents indicated that the OPAC was their first choice of information source, as was seen in the previous section.

Reasons for this anomaly could be that:

I. Students are not sure how to locate resources using the OPAC; or

2. They do not really know how to browse, as the books on the open shelves are listed by classification/location numbers. This can cause problems for first time library users.

Asking library staff for assistance was less popular, and the smallest number of respondents $(8 ; 3 \%)$ indicated that they trusted their friends to help them to locate library sources. This could be that they are either afraid to ask or are unable to use the OPAC or to browse on the shelves.

\subsection{Location of encyclopaedias}

In an attempt to test students' familiarity with the arrangement and location of library materials, respondents were asked to name the section of the library where encyclopaedias are kept. The findings are summarised in Table 3:

Table 3 Location of the encyclopaedias $(\mathrm{N}=246)$

\begin{tabular}{lll}
\hline Location & Respondents & Percentage \\
\hline Reference section & 104 & 42 \\
I do not know & 98 & 40 \\
Open shelves & 17 & 7 \\
Periodicals section & 17 & 7 \\
Short-Loan & 10 & 4 \\
Africana & 0 & 0 \\
\hline TOTAL & $\mathbf{2 4 6}$ & $\mathbf{1 0 0}$
\end{tabular}

Fewer than half of the respondents (104; 42\%) correctly named the reference section as the place where encyclopaedias are kept. This clearly indicates that the majority of respondents are not familiar with the location of some of the most basic library sources.

\subsection{Knowledge of the classification scheme}

In order to assess whether students had any knowledge of the classification scheme used in the library, they were asked: 'If a book has a shelf number 350: what would that book be about?' Findings are summarised in Table 4:

Table 4 Understanding location numbers $(\mathrm{N}=246)$

\begin{tabular}{lll}
\hline Discipline & Respondents & Percentage \\
\hline I do not know & 146 & 59 \\
Sociology & 48 & 20 \\
Public administration & 43 & 17 \\
Library science & 9 & 4 \\
\hline TOTAL & $\mathbf{2 4 6}$ & $\mathbf{1 0 0}$ \\
\hline
\end{tabular}


It was clear that the majority of respondents did not seem to understand location numbers, although the classification numbers are prominently posted in the library. Only 43 (17\%) knew that "350" is the Dewey Decimal Classification number for Public Administration. Of the rest, I 46 (59\%) were unable to tell and a total of 57 (23\%) chose incorrect disciplines.

\subsection{Journal usage}

In order to test whether students were familiar with the journals collection, respondents were asked to name the titles of any three journals they had used in the library. It was found that $104(42 \%)$ answered the question correctly by naming various journal titles in the library. A few $(7 ; 3 \%)$ failed to give journal titles; instead they gave titles of books that they had used in the library. Another 7 (3\%) said that they had never used journals in the library. Blank spaces were left by 128 $(52 \%)$ and this could indicate that:

I. They had never used journal in the library

2. They did not know what journals were

3. They could not remember or were not prepared to write down the titles of journals they had used in the library.

\subsection{Training in the use of online resources}

Respondents were asked to indicate whether they had received any training in the use of online resources. Each respondent was required to select as many options as applied.

A total of 300 responses were received. Most respondents $(115 ; 38 \%)$ indicated that they had received training in the use of the Internet, while 76 (25\%) said they had received OPAC training. Only 14 respondents (5\%) indicated that they had received training in the online databases. This finding is a cause for concern, as librarians spend considerable amounts of time in training students to use these expensive resources.

Although 95 (32\%) indicated that they had never received training in the use of online resources, this does not necessarily mean they do not know or are unable to use these resources. They might either have taught themselves, or may be given assistance from friends or from the library staff.

\subsection{Internet use}

Using the Internet is very popular. The University of Fort Hare is no exception. Students use it for various purposes, regardless of whether they had been trained or not. To determine the extent of Internet usage at the University of Fort Hare, respondents were asked for which purposes they use the Internet. Five options were provided and each respondent could tick as many as applied. The last option was for those who did not know how to use the Internet. The findings are summarised in Table 5:

Table 5 Uses of the Internet

\begin{tabular}{lll}
\hline Internet activities & Responses & Percentage of respondents \\
\hline Surfing for information & 209 & 85 \\
E-mail & 180 & 73 \\
Sending short message services (sms) & 142 & 58 \\
Chatting & 60 & 24 \\
Playing games & 50 & 20 \\
No knowledge of the Internet & 14 & 6 \\
\hline TOTAL & $\mathbf{6 5 5}$ & $\mathbf{N}=\mathbf{2 4 6}$ \\
\hline
\end{tabular}

Table 5 shows that the Internet is used for various purposes, not all of which are academic. The most popular activity was 'surfing for information' which was selected by 209 out of a total of 246 respondents (85\%). Only 14 (6\%) respondents admitted to not knowing how to use the Internet. Social activities such as electronic mail, sending short messages and chatting, together elicited a total of 382 of responses, showing that many students engage in two or more of these communication activities. In addition, $50(20 \%)$ use the Internet to play games. This suggests that although a large majority of respondents are clearly familiar with the Internet, it is to a considerable extent used for non-academic activities.

\subsection{Evaluation of Internet sources}

Respondents who said they had received Internet training were asked whether they could tell whether a web source is worth using. Positive responses were given by 69 out of a total of I I 5 responses (60\%), while the remaining 46 (40\%) indicated that in spite of having received training in the effective use of the Internet including the evaluation of Internet sources, they still do not know how to tell whether a web source is worth using. 
To gain further insight into students' ability to evaluate Internet sources, those 69 respondents who said they knew how to tell whether a web source is worth using, were asked to name any three things that they would look at, to check if the information is worthwhile.

From this number (69), correct answers were provided by only 18 respondents $(26 \%)$. They suggested that one has to check:

I. Author and authors' credentials

2. Credibility of the site

3. Date the site was created and up-dated

4. Check if there are any spelling errors

5. Check if the address or e-mail to contact the author is provided.

The majority of the respondents $(51 ; 74 \%)$ gave incorrect answers. This suggests that in spite of having received Internet training, they still did not know how to tell whether a web source is worth using.

\subsection{Citation and plagiarism}

Everyone who uses secondary sources like books, online databases and Internet resources, is required to acknowledge the bibliographical details of sources used. When respondents were asked whether they knew how to cite Internet sources when compiling a bibliography, I 18 (48\%) respondents claimed that they knew, and $128(52 \%)$ responded by saying they did not know how to cite Internet sources. This seems to indicate that some respondents (with the exception of those who did not know how to use the Internet in the first place) make use of other people's words and ideas without knowing how to acknowledge them. Having done so, they therefore might be guilty of plagiarism.

\subsection{Use of the library web page}

The library has a web site where relevant information such as links to online databases, dictionaries encyclopaedias and newspapers, help on the evaluation of online resources, library hours, library rules and staff details is found. To check the usage of this site, respondents were asked to indicate how often they access the library web page and also how helpful they found it.

Table 6 Frequency of using library web page $(N=246)$

\begin{tabular}{lll}
\hline Responses & Respondents & Percentage \\
\hline I - 4 times a week & 82 & 33 \\
I - 4 times per month & 52 & 21 \\
Every working day & 32 & 13 \\
Never & 49 & 20 \\
I did not know about the page & 31 & 13 \\
\hline TOTAL & $\mathbf{2 4 6}$ & 100 \\
\hline
\end{tabular}

Table 6 shows that a total of 166 students $(67 \%)$ accessed the library web page at least once a month or more often. A lack of marketing of library services and especially of the library web page, could be the reason why 31 (I3\%) responded that they did not know the library had a web page.

A follow-up question asking how helpful they found the web page, showed that I 28 (52\%;) found the site helpful and 41 (17\%) did not. No comment was made by 77 (31\%) who simply left blank spaces. This quite closely matches the responses to the previous question (Table 6), which showed that a total of $33 \%$ never accessed the library web page or did not know the library had one.

\section{Conclusion and recommendations}

The study set out to determine the extent to which the University of Fort Hare Library equips students with information skills for their academic careers. Findings have shown that while some students do participate in information skills training and seem able to use information resources, there remains considerable scope for improvement. The main findings were: I. More than half the students do not attend library orientation sessions in spite of their being compulsory. This omission is probably caused by late admissions.

2. Even if students do attend library orientation sessions, they do not learn a great deal more than how to photocopy and what the library rules are.

3. Students do not seem to be very confident in using the OPAC; many were not familiar with reference sources or journals and seemed not to understand the classification scheme.

4. Using the Internet is a popular way to search for information, but it is also extensively used for non-academic purposes.

SA Jnl Libs \& Info Sci 2005, $71(3)$ 
In order for the library to function well and generate graduates with skills for lifelong learning the following are recommended:

I. Fort Hare Library should revise its mission statement which focuses on providing appropriate information sources and training users in the retrieval of information, as it is not sufficient. The new mission statement should include other components of information literacy such as evaluation skills and avoidance of plagiarism. Sayed and De Jager support this suggestion by asserting that 'the ability to access and manipulate information from various sources is necessary but not sufficient' (1997:6). Grassian and Kapplowitz (200 I: I I I) also support the researchers by maintaining that learning to think critically is one of the most important goals of undergraduate education, and indeed for lifelong learning. It is not the process of finding information that is important, but what people do with it when they find it. If they are able to think critically, they are able to distinguish fact from fiction.

2. Plagiarism on the Internet is rife and higher education institutions have adopted policies for making their students aware of it. Although the University of Fort Hare like other higher education institutions is aware of the problem, it does not have a documented policy on plagiarism. A university policy in the effective use of Internet and combating plagiarism should to be drafted as a matter of urgency and then implemented.

3. The integration of computer literacy into the university curriculum rather than merely providing an expensive add-on programme will benefit the majority of students.

4. A formal library orientation committee should be established and orientation should be conducted on regular basis. The task of the committee should be planning, organizing and evaluating the orientation programme such as course content, duration, teaching methods to be used and size of the group.

5. A programme of promoting library services should be implemented as a matter of urgency. If the library seeks to render quality service and attract more users, it should start devising and drafting an appropriate strategy on marketing. Marketing will help the users to take full advantage of library services that are currently less used, especially the subscription databases and library web page.

Globalization and technological advances have affected the ways people conduct their business. Learning to think critically is one of the fundamental goals of information literacy, which in return contributes to lifelong learning. Empowering students with the essential information skills will enable them to think critically, to distinguish fact from fiction and reliable from unreliable sources of information. New roles require librarians in collaboration with academic staff and other stakeholders is to engage in student learning, as students will not function effectively and competently when they lack the required information skills to manipulate and use information. This study has shown that while the University of Fort Hare Library is aware of the importance of developing students' information literacy, it still has a long way to go in helping students become lifelong learners.

\section{References}

Adler, R.P. 1999. Information literacy: advancing opportunities for learning in the digital age. [Online]. Available: http:// www. aspeninst.org/aspeninstitute/files/lmg/pdf/infolit.pdf

[Site re-visited on 10/06/2005]

(ALA) American Library Association. 1989. Presidential committee on information literacy: a final draft. [Online]. Available: http://www.ala.org/acrl/acrlpubs/whitepapers/presidential.htm

[Site re-visited on 10/06/2005]

Behrens, S.J. 1992. Librarians and information literacy. Mousaion. 10(I): 81-88.

Brandt, D.S. 200I. Information technology literacy: task knowledge and mental models. Library trends. 50(I): 73. [EBSCO Online]. Available: $h t t p: / /$ search.epnet.com [Site re-visited on 10/6/2005]

Bruce, C.S. 1997. Seven faces of information literacy. Adelaide: Aslib Press.

Bundy, A. 200I. For a clever country: information literacy diffusion in the $21^{\text {st }}$ century. [Online]. Available: http:// www.library.unisa.edu.au/about/papers/clever.htm

[Site re-visited on 10/06/2005]

De Jager, K. and Nassimbeni, M. 2002. Institutionalizing information literacy in tertiary education: lesson learned from South African programmes. Library trends. 5I(2): 167-184. [EBSCO Online]. Available: http://search.epnet.com [Site re-visited on 10/06/2005]

De Jager, K. and Nassimbeni, M. 2003. An exploration of the current status of information literacy tuition in South African tertiary institutions and proposals for curriculum design. South African journal of libraries and information science. 69(2): $108-1$ I 4.

De Jager, K. and Nassimbeni, M. 2005. Information literacy and quality assurance in South African Higher Education Institutions. Libri. 55(I): 31-38.

Doyle, C.S. 2003. A concept for the information age. [Online]. Available: http://learning.kern.org/tlc_resources/stories/ storyReader $\$ 25$ [Site re-visited on 10/06/2005]

Fahey, N. 2003. The importance of addressing accepted training needs when designing electronic information literacy training. Information science journal. 6: 173-185.

Grassian, E.S. and Kapplowitz, J.R. 200I. Information literacy instruction: theory and practice. New York: Neal-Schuman. 
Haberle, N. 2002. Developing a theoretical evaluative framework for information literacy interventions: a South African initiative. South African journal of higher education. 16(3): 21-30.

Langford, L. 1999. Information literacy? seeking clarification. [Online]. Available: http://golum.riv.csu.edu.au/ /langfor/papers/ paper5.html [Site re-visited 10/06/2005]

Makhubela, L. and Koen, Z. 1995. Another angle on access: information literacy and student learning. Academic development. I(I): I3-19.

McClure, C.R. 1994. Network literacy: a role for libraries? Information technology and libraries. I3(2): II 5- I 25.

Sayed, Y. and De Jager, K. 1997. Towards an investigation of information literacy in South Africa. South African journal of library and information science. 65(I): 5. [EBSCO Online]. Available: http://search.epnet.com [Site re-visited on 10/06/2005]

Tiefel, V.M. Library user education: examining its past, projecting its future. Library trends. 44(2): 3I8-338.

University of Fort Hare. 2004. General prospectus. 